\title{
Post exposure prophylaxis for occupational and non occupational exposure to HIV in a tertiary care hospital in central Nepal
}

\author{
Rakshya Shrestha ${ }^{1}$, Sashi Sharma ${ }^{1}$, Prem Khadga ${ }^{1}$, Matina Sayami $^{1}$, Uma Chitrakar $^{1}$, Govinda Prasad Dhungana ${ }^{2}$ \\ ${ }^{1}$ Tribhuvan University Teaching Hospital Maharajgunj, Kathmandu, Nepal \\ ${ }^{2}$ Department of Microbiology, Far-Western University, Mahendranagar, Kanchanpur, Nepal
}

DOI: https://doi.org/10.3126/jaim.v7i2.23488

Keywords: HIV, Needle-prick, prophylaxis,

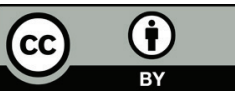

This work is licensed under a Creative Commons Attribution 3.0 Unported License.

\section{Introduction}

Post exposure prophylaxis (PEP) for exposure to HIV is the short-term use of prescribed dose of antiretroviral (ARV) drugs to help prevent HIV transmission. The ARV drugs are given immediately after exposure so that it can stop the virus from disseminating in the body and establishing infection. ${ }^{1}$ The average risk for HIV transmission after a percutaneous exposure to HIV-infected blood has been estimated to be approximately $0.3 \%$ and after a mucous membrane exposure, approximately $0.09 \%, 2,3$

\begin{abstract}
Introduction: Post exposure prophylaxis (PEP) to HIV is the short term use of prescribed dose of antiretroviral therapy among persons exposed to high risk behaviors in order to prevent them from HIV infection. While occupationally exposed cases among health care workers are the major target of PEP, it is equally applicable to non occupational exposure to HIV including sexually exposed cases. This study was carried out to know the current scenario of PEP for HIV in terms of various determinants/ risk factors and outcomes of HIV positivity after prophylaxis.

Methods: A prospective study was carried out by Antiretroviral therapy center of Tribhuvan University Teaching Hospital. The study period was between August 2006 and September 2016. Altogether 50 cases exposed to known HIV seropositive persons were included in this study.

Results: The majority of the occupationally exposures were interns $(48.6 \%)$, followed by staff nurse $(18.9 \%)$, CMLT student (13.5\%), hospital staff (10.8\%) and resident doctor $(8.1 \%)$. Majority $(70.3 \%)$ were exposed to needle prick injury. Six-month follow-up showed zero seroconversion for HIV ELISA among the exposed cases.

Conclusion: Intern constituted the greater proportion of health care workers exposed to accidental needle stick injury. Timely administration of prophylaxis might have resulted zero seroconversion for HIV ELISA among the exposed cases.
\end{abstract}


Needle prick injury was the commonest form of exposure. ${ }^{4-6}$ Currently, no studies on PEP are carried out in Nepal except a knowledge and practice (KAP) of nurses on post exposure prophylaxis of HIV in Chitwan medical College. ${ }^{7}$

This prospective study was carried out among exposures visiting Tribhuvan University Teaching Hospital to document the scenario of PEP for HIV in terms of various determinants and outcomes of HIV positivity after prophylaxis.

\section{Methods:}

A prospective study was carried out by HIV/AIDS unit, Tribhuvan University Teaching Hospital, Kathmandu, between August 2006 and September 2016. Both occupational and non occupational exposures to HIV were included in this study. Decision whether PEP should be provided or not is made by clinician on a caseby -case basis and their entry into PEP programme was made by first come first service basis. Altogether, 50 PEP seekers were included in this study. The major inclusion criteria were the exposed person is HIV negative and source person is HIV positive. While taking informed consent for HIV PEP, they were made fully aware about the risk of acquiring HIV infection for the specific exposure and the necessity of doing base line HIV test and about the importance of post test counseling, adherence to prophylaxis and regular follow for health check up. Then, in depth interview was taken and information was entered into prestructured questionnaire. In addition to general demographic information, more specific information was collected to identify the nature of exposure and risks. Categorization of risks was done as follows:

High risk: Deep, skin-penetrating injury with large-bore needle or sharp objects with visible blood.

Minimal risk: Contact with mucous membrane and non intact skin i.e eyes, mouth, skin rash, scratch, abrasion.

No risk: Contact with normal unbroken skin.

As per National consolidated guidelines for treating and preventing HIV in Nepal (2014), the prophylaxis was given for 28 days and the first dose was given as soon as possible with in 72 hours of exposure. The regimen were Tenofovir/Lamivudine (TDF/3TC) x1 (OD) + Lopinavir/Ritonavir (LPV/rTV) x2 (BD).

During the course of prophylaxis, its monitoring was done at prescribed time interval. HIV ELISA was performed at the baseline, and three and six month of post exposure. Liver function test and other tests such as Hemoglobin percentage, total WBC count, and differential WBC count were done after two weeks of prophylaxis. The collected data were entered into SPSS 11.5 and analyzed.

\section{Results}

Out of 50 exposures, baseline HIV test was done for all and all were HIV Non reactive. Two cases of exposures did not visit for follow up. As per national consolidated guidelines for treating and preventing HIV in Nepal (2014), HIV testing was done for remaining 48 cases after 3 months, and in this study all were non reactive. Confirmatory HIV test after 6 months of exposure was also done and till date, no case of HIV reactivity was observed.

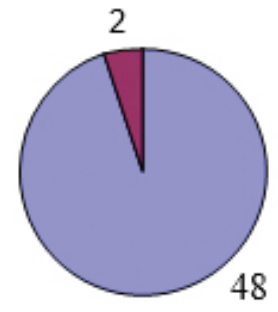

\section{$\square$ No HIV seropositivity after PEP \\ $\square$ Loss of follow up}

Among 50 persons, 24 (48\%) were male and $26(52 \%)$ were female. Majority $(90.0 \%)$ of them were in the age group 21- 40 years. The remaining $(10.0 \%)$ were in the age group 1-20 years. Undergraduate students (intermediate plus bachelor) constituted the major proportion of PEP seekers accounting as high as $72.0 \%$ as shown in table 1 .

Table 1: Socio-demographic features of studied subjects

\begin{tabular}{|l|c|c|c|}
\hline \multirow{2}{*}{ Feature } & \multicolumn{2}{|c|}{ Sex } & Total \\
\cline { 2 - 4 } & $\begin{array}{c}\text { Male } \\
\text { Number (\%) }\end{array}$ & $\begin{array}{c}\text { Female } \\
\text { Number (\%) }\end{array}$ & \\
\hline
\end{tabular}

\begin{tabular}{|l|l|l|l|}
\hline \multicolumn{4}{|l|}{ Age group } \\
\hline $1-20$ & $2(8.3)$ & $3(11.5)$ & $5(10.0)$ \\
\hline $21-40$ & $22(91.7)$ & $23(88.5)$ & $45(90.0)$ \\
\hline Total & $24(100)$ & $26(100)$ & $50(100)$ \\
\hline
\end{tabular}

\begin{tabular}{|l|l|l|l|}
\hline Education \\
\hline Just literate & $7(29.1)$ & $5(19.2)$ & $12(24.0)$ \\
\hline Intermediate & $4(16.8)$ & $12(46.2)$ & $16(32.0)$ \\
\hline Bachelor & $11(45.8)$ & $9(34.6)$ & $20(40.0)$ \\
\hline Master & $2(8.3)$ & 0 & $2(4.0)$ \\
\hline Total & $24(100)$ & $26(100)$ & $50(100)$ \\
\hline
\end{tabular}

Regarding exposure type, $74.0 \%$ of the PEP receivers were occupationally exposed to known HIV infected persons. Among thirteen non occupational cases, ten were male as shown in table 2.

Table 2: Distribution of studied subjects by exposure type and gender

\begin{tabular}{|l|l|l|l|}
\hline \multirow{2}{*}{$\begin{array}{l}\text { Exposure } \\
\text { type }\end{array}$} & \multicolumn{2}{|c|}{ Sex } & Total \\
\cline { 2 - 4 } & $\begin{array}{c}\text { Male } \\
\text { Number (\%) }\end{array}$ & $\begin{array}{c}\text { female } \\
\text { Number }(\%)\end{array}$ & \\
\hline Occupational & $14(58.3)$ & $23(88.5)$ & $37(74.0)$ \\
\hline $\begin{array}{l}\text { Non } \\
\text { occupational }\end{array}$ & $10(41.7)$ & $3(11.5)$ & $13(26.0)$ \\
\hline Total & $24(100)$ & $26(100)$ & $50(100)$ \\
\hline
\end{tabular}


Among 37 occupationally exposed cases, 18 (48.6\%) were intern followed by staff nurse (18.9\%), CMLT student (13.5\%), hospital staff $(10.8 \%)$ and resident doctor $(8.1 \%)$ as shown in table 3 .

\begin{tabular}{|l|l|l|l|}
\hline \multirow{2}{*}{ Table 3: Distribution of occupationally exposed cases by occupation and gender } \\
\cline { 2 - 4 } & \multicolumn{1}{|c|}{$\begin{array}{c}\text { Male } \\
\text { Number (\%) }\end{array}$} & \multicolumn{1}{c|}{$\begin{array}{c}\text { female } \\
\text { Number (\%) }\end{array}$} & \\
\hline Intern & $10(71.4)$ & $8(34.7)$ & $18(48.6)$ \\
\hline Staff nurse & 0 & $7(30.4)$ & $7(18.9)$ \\
\hline CMLT student & $2(14.3)$ & $3(13.0)$ & $5(13.5)$ \\
\hline Hospital staff & 0 & $4(17.4)$ & $4(10.8)$ \\
\hline Resident doctor & $2(14.3)$ & $1(4.4)$ & $3(8.1)$ \\
\hline Total & $14(100)$ & $23(100)$ & $37(100)$ \\
\hline
\end{tabular}

Among 37 occupationally exposed cases, majority (70.3\%) were exposed to needle prick injury. Others were exposed to mucous membrane during procedure (13.5\%), blood splash (10.8\%) and cut wound blood exposure (5.4\%) as shown in table 4.

\begin{tabular}{|c|c|c|c|}
\hline \multirow[t]{2}{*}{ Nature of exposure } & \multicolumn{2}{|c|}{ Sex } & \multirow[t]{2}{*}{ Total } \\
\hline & $\begin{array}{c}\text { Male } \\
\text { Number (\%) }\end{array}$ & $\begin{array}{c}\text { female } \\
\text { Number (\%) }\end{array}$ & \\
\hline \multicolumn{4}{|l|}{ Occupational } \\
\hline Needle prick & $11(78.6)$ & $15(65.3)$ & $26(70.3)$ \\
\hline Mucous membrane & $2(14.3)$ & $3(13.0)$ & $5(13.5)$ \\
\hline Blood splash & $1(7.1)$ & $3(13.0)$ & $4(10.8)$ \\
\hline \begin{tabular}{|l|} 
Cut wound blood contact \\
\end{tabular} & 0 & $2(8.7)$ & $2(5.4)$ \\
\hline Total & $14(100)$ & $23(100)$ & $37(100)$ \\
\hline \multicolumn{4}{|l|}{ Non occupational } \\
\hline Sexual & $9(90)$ & $2(66.7)$ & $11(84.6)$ \\
\hline Cut wound blood contact & $1(10)$ & $1(33.3)$ & $2(15.4)$ \\
\hline Total & $10(100)$ & $3(100)$ & $13(100)$ \\
\hline
\end{tabular}

Needle prick injury was observed in all occupationally cases. In addition to this, few intern and staff nurse were exposed to mucous membrane, blood splash and cut wound . Non-occupationally exposed cases were predominantly by sexual means accounting $84.6 \%$ of the cases.

\begin{tabular}{|c|c|c|c|c|c|}
\hline \multirow[t]{2}{*}{ occupation } & \multicolumn{5}{|c|}{ Nature of exposure } \\
\hline & $\begin{array}{l}\text { Needle prick } \\
\text { Number (\%) }\end{array}$ & $\begin{array}{c}\text { mucous membrane } \\
\text { Number (\%) }\end{array}$ & $\begin{array}{l}\text { blood splash } \\
\text { Number (\%) }\end{array}$ & $\begin{array}{c}\text { sexual } \\
\text { Number (\%) }\end{array}$ & $\begin{array}{c}\text { cut wound } \\
\text { Number (\%) }\end{array}$ \\
\hline Intern & $13(50.0)$ & $3(60)$ & $2(50)$ & 0 & 0 \\
\hline Staff nurse & $2(7.7)$ & $2(40)$ & $2(50)$ & 0 & $1(25)$ \\
\hline CMLT student & $5(19.2)$ & 0 & 0 & 0 & 0 \\
\hline Hospital staff & $4(15.4)$ & 0 & 0 & 0 & 0 \\
\hline Resident doctor & $2(7.7)$ & 0 & 0 & 0 & $1(25)$ \\
\hline Non occupational & 0 & 0 & 0 & 11(100) & $2(50)$ \\
\hline Total & $26(100)$ & $5(100)$ & $4(100)$ & $11(100)$ & $4(100)$ \\
\hline
\end{tabular}




\section{Discussion}

In our study, the majority of the occupationally exposures were interns (48.6\%), followed by staff nurse (18.9\%), CMLT student (13.5\%), hospital staff (10.8\%) and resident doctor (8.1\%). Interns form a small proportion of the medical or nursing staff in a teaching hospital, but accounted for a large proportion of the injuries. This can be a reflection of the larger number of exposure-prone procedures conducted by these categories. Another important finding of this study was that majority $(70.3 \%)$ were exposed to needle prick injury. Therefore on the basis of this study it can be recommended that hospital should adopt provide extra attention strategies targeting interns to reduce the chance of HIV infection by accidental needle stick injury among this group of health care workers (HCWs). A similar study carried out in Christian Medical College, Vellore Tamil Nadu reported that intern constituted the $9.1 \%$ of cases exposed to accidental needle stick injury. ${ }^{8}$

Six-month follow-up showed zero seroconversion for HIV ELISA, which is similar to the other studies in India. ${ }^{6,9}$ Worldwide, there are 296 cases of HIV seroconversion after occupational exposure, of which 56 are documented while 138 are possibly occupationally acquired. ${ }^{10}$ In Nepal, there is no documented evidences reporting the occupationally acquired HIV infection.

Although this study is based on the data of 10 years only 31 recorded cases of occupational exposures among health care workers seeking PEP in a tertiary care hospital of central Nepal. A similar study in a tertiary care hospital in India (Christian Medical College, Vellore Tamil Nadu) reported 296 HCWs seeking PEP with in a year of study. This reflects that there may be lack of communication between PEP seekers and PEP providers. This is also supported by the fact that only $6 \%$ of Nurses in Chitwan Medical College Teaching Hospital had good knowledge on PEP.7 Therefore, special PEP awareness program should be conducted that may increase the number of HCWs seeking PEP. Furthermore, ELISA after 6 months of the initiation of therapy could not be done for two persons due to los of follow up. Therefore special attention should be given during counseling to increase the adherence to prophylaxis. One of the interesting findings of this study is that male to female ratio for occupationally and non occupationally exposed cases is quite different.

Table 2 shows that male to female ratio for occupationally exposed cases are 14:23 while for non occupationally exposed cases the ratio is 10:3. This may be due to the fact that in health care setting female population constitutes the major proportion of health care workers, and greater numbers of males are involved in highly risky sexual activities then females in non health care settings. Post exposure prophylaxis for HIV in health care workers in Gujarat scenario has also demonstrated the higher proportion of females health care workers (male : female ratio is 101: 177) among the exposed cases.4 On the basis of this study it can be recommended that different types of prevention strategies should be adopted by public agencies, medical college/hospitals, nongovernmental organizations and International non- governmental organizations according to the target groups (i.e occupational or non occupational) to prevent from HIV infection.

\section{Conclusion}

Intern constituted the greater proportion of health care workers seeking PEP. Majority of the HCWs are exposed to accidental needle stick injury. Timely administration of prophylaxis might have resulted zero seroconversion for HIV ELISA among the exposed cases. Specific PEP awareness program should be conducted by different sectors such as, public agencies, medical college/hospitals, non-governmental organizations and International non-governmental organizations that may increase the number of HCWs seeking PEP.

\section{Acknonwledgement}

We would like to express sincere thanks to all the HCWs and other PEP seekers for participating in this study. We are equally thankful to all the staffs of HIV/AIDS unit Tribhuvan University Teaching Hospital for their support during the entire period of study.

\section{References}

1. National consolidated guidelines for treating and preventing HIV in Nepal. Government of Nepal, Ministry of health and population and National center for AIDS and STI control (NCASC), 2014, Kathmandu, Nepal.

2. Bell DM. Occupational risk of human immunodeficiency virus infection in healthcare workers: an overview. Am J Med. 1997;102(5B):9-15.

3. Ippolito G, Puro V, De Carli G. The Italian Study Group on Occupational Risk of HIV infection. Arch Intern Med. The risk of occupational human immunodeficiency virus infection in health care workers: Italian Multicenter Study. Arch Intern Med. 1993;153(12):1451-8.

4. Shevkani M, Kavina B, Kumar P, et al. An overview of post exposure prophylaxis for HIV in health care personals: Gujarat scenario. Indian J Sex Transm Dis. 2011 Jan-Jun; 32(1): 9-13

5. Management of Occupational exposure including Post exposure prophylaxis for HIV. New Delhi: NACO, Ministry of Health and Family Welfare, Government of India; 2009. National AIDS Control Organization.

6. Mehta A, Rodrigues $\mathrm{C}$, Ghag S, et al. Needlestick injuries in a tertiary care centre in Mumbai, India. J Hosp Infect

7. Lamichanne J, Aryal B, Dhakal K S. Knowledge of Nurses on post exposure prophylaxis of HIV in Medical Colleges of Chitwan District, Nepal. Int J Pharm Biolog Arch. 2012;3(6):1394-9.

8. Jayanth ST, Kirupakaran H, Brahmadathan KN, et al. Needle sticke injuries in a tertiary care hospital. Indian Journal of Medical Microbiology, 2009; 27(1): 44.

9. Richard VS, Kenneth J, Ramaprabha P, et al. Impact of introduction of sharps containers and of education programmes on the pattern of needle stick injuries in a tertiary care centre in India. J Hosp Infect 2001;47:163-5

10. Perry J, Parker G, Jagger J. EPINET report: 2003 percutaneous injury rates. Adv Exposure Prev 2005;7:2-45. 